Research Article

\title{
Frailty and Nutritional Status among Urban Older Adults in South India
}

\author{
T. Shalini, ${ }^{1}$ P. Swathi Chitra, ${ }^{1}$ B. Naveen Kumar, ${ }^{2}$ G. Madhavi, ${ }^{3}$ \\ and G. Bhanuprakash Reddy $\left({ }^{1}\right.$ \\ ${ }^{1}$ Department of Biochemistry, ICMR-National Institute of Nutrition, Jamai-Osmania, Tarnaka, Hyderabad, Telangana, India \\ ${ }^{2}$ Department of Statistics, ICMR-National Institute of Nutrition, Jamai-Osmania, Tarnaka, Hyderabad, Telangana, India \\ ${ }^{3}$ Department of Community Studies, ICMR-National Institute of Nutrition, Jamai-Osmania, Tarnaka, Hyderabad, \\ Telangana, India
}

Correspondence should be addressed to G. Bhanuprakash Reddy; geereddy@yahoo.com

Received 23 October 2019; Revised 14 May 2020; Accepted 13 June 2020; Published 10 July 2020

Academic Editor: Barbara Shukitt-Hale

Copyright (c) 2020 T. Shalini et al. This is an open access article distributed under the Creative Commons Attribution License, which permits unrestricted use, distribution, and reproduction in any medium, provided the original work is properly cited.

\begin{abstract}
The purpose of this study was to assess the prevalence of frailty and nutritional status among older adults. This population-based cross-sectional study was conducted in 163 subjects aged 60-88 years, from Hyderabad City, South India. Data were obtained on sociodemographic details and anthropometry and biochemical parameters. Dietary intake was assessed by a three-day $24 \mathrm{~h}$ dietary recall, and the probability of adequacy (PA) was calculated using the estimated average requirements. Frailty indicators were as follows: handgrip strength was measured by using a Jamar dynamometer, gait speed was measured by a ten-meter length walk test, and low physical activity level, weight loss, and exhaustion were assessed using a questionnaire. Among the study population, $20 \%$ of the participants were frail and $80 \%$ were nonfrail. The prevalence of frailty is higher in older (30.1\%) than the younger (12.2\%) age groups, and it is more so in women $(32.4 \%)$ than in men $(10.1 \%)$. The lower educational status and income were associated with frailty. The PA of most of the nutrients was low in the frail group. Noticeably, the mean PA (MPA) across the fourteen micronutrients was significantly higher in nonfrail (38\%) compared to the frail group (25\%). The prevalence of frailty was higher in the lowest tertile of most of the food groups and nutrient intake compared to the highest tertile. The study revealed a $20 \%$ prevalence of frailty among urban older adults and provided evidence that inadequate intake of nutrients is independently associated with frailty.
\end{abstract}

\section{Introduction}

The average life span of humans at birth has been increased in the last century, approximately from 45 years (the early 1900 s) to 80 years today. It is estimated that by 2050 , about $21.5 \%$ ( 2 billion) of the global population will be over 60 years of age $[1,2]$. This demographic transition of increased life expectancy is associated with the burden of several agerelated disorders, including frailty [3]. Frailty, a biologic or geriatric syndrome characterized by multisystem dysregulation leading to a loss of dynamic homeostasis, decreased physiological, functional, and cognitive reserves that confer vulnerability to adverse outcomes. Frail people are at a higher risk of disability, falls, cognitive impairment, hospitalization, dependence, and mortality, hence becoming a major clinical and public health concern $[3,4]$.

There are over 25 subjective and objective frailty assessment methods developed globally to assess frailty with many different intangible definitions. The most followed methods of measurement include the Rockwood frailty index, which defines frailty as a result of several age-related deficits that may lead to poor health [5]. The second method developed by Fried defines frailty as a unidimensional, principally physical domain which includes three of five indicators such as exhaustion, weak grip strength, low energy expenditure, slow walking speed, and weight loss [6]. However, other researchers have proposed to include the cognitive domain, a multidimensional construct, which 
could aid in a better understanding of the frailty phenotypes and pathways to adverse outcomes [7].

The quality of life of aging people can be improved if intervened at an early stage of functional decline by slowing, delaying, or partly reversing the state of frailty, if assessed appropriately [8]. Poor nutritional status is one of the factors found to be associated with frailty, which might be due to insufficient food intake. Epidemiological studies have reported that dietary protein content, protein quality, and micronutrients could play a crucial role in the development and management of aging and frailty [9]. Moreover, adequate intakes of macronutrients and micronutrients have been found to reduce the risk of frailty [10].

In developing countries such as India, frailty assessment among older adults has seldom received the attention of the investigators. Few studies reported varied prevalence (16.3-55.5\%) of frailty in India [11-13], while some studies emphasized on physical, cognitive, and depression domains separately $[14,15]$, but a comprehensive approach towards frailty assessment, particularly nutritional component, is missing. Therefore, the present study was conducted (i) to assess the prevalence of frailty among urban older adults using the Fried frailty phenotype criteria and (ii) to assess their nutritional status.

\section{Methods}

2.1. Study Design, Sample Size, and Recruitment of Subjects. This population-based cross-sectional study was conducted among older adults aged 60 years and above in the urban areas of Hyderabad Metro City, Telangana State, India, from November 2016 to July 2017. Based on the reported prevalence of frailty among older adults as $56 \%$, the sample size was calculated [11]. Assuming a 95\% confidence interval (CI) with a relative precision of $20 \%$, the sample size arrived was 78 . However, with a design effect of 2 , the sample size comes to 156 .

The Hyderabad City was stratified into four zones (south, east, west, and north), and two wards were selected from each zone by a simple random sampling procedure to capture the entire population of the city. To enroll participants, health camps were organized at randomly selected wards. From each ward, four locations were selected, and in each location, one health camp was organized. Approximately, 20 subjects were approached in each health camp. The details of the selection and recruitment of the study participants are depicted in Figure 1. A total of 163 participants, 89 men and 74 women, who fulfilled the criteria (mentioned in Figure 1) have consented for participation.

The study was conducted according to the guidelines laid down in the 1964 Declaration of Helsinki and its later amendments. All procedures involving human participants were approved by the Institutional Ethics Committee (ethical approval number: IEC; \# CR9/I/2014). Written informed consent (or thumb impression in the case of illiterates) was obtained from the participants who volunteered to participate in the study.
2.2. Data Collection. Sociodemographic information such as age, literacy status, cohabitate details, food habits, and selfreported comorbid conditions was obtained using a questionnaire. Participants were categorized into two groups based on their food habits. Those who never consumed animal foods (such as poultry, meat, eggs, and fish) were included in the vegetarian group, and the others who consumed both animal foods and plant foods were included in the mixed diet group.

2.2.1. Anthropometric Measurements. The body weight and height were recorded using the SECA weighing scale and anthropometric rod, respectively, and the body mass index (BMI) was calculated. Waist circumference (WC) was measured using a fiber-reinforced nonelastic tape at a point midway between the lower rib region and the iliac crest, and hip circumference (HC) was measured by passing the tape over maximum protuberance on buttocks. Asian cutoff values were used for BMI classification [16] and defining abdominal and central obesity [17]. Blood pressure (BP) was measured thrice with a five-minute interval between each measurement using a BP apparatus, and the average of three readings was taken. Participants with systolic blood pressure (SBP) of $\geq 140 \mathrm{mmHg}$ and diastolic blood pressure (DBP) of $\geq 90 \mathrm{mmHg}$ and/or those participants on antihypertensive medication were considered hypertensive [18].

2.2.2. Biochemical Estimations. Fasting venous blood samples were collected in heparin tubes early in the morning following overnight fast, and spot urine samples (firstmorning void) were collected in sterile urine containers. The samples were transported to the laboratory in the icebox for further analysis. Blood and plasma were separated by centrifugation at $3500 \mathrm{rpm}$ for $10 \mathrm{mins}$. Fasting blood glucose (FBG) was estimated in whole blood using an Accu-Chek Active glucometer [19]. Glycosylated haemoglobin (HbA1c) was estimated by an Afinion AS100 Analyzer (Axis-Shield, Norway) based on the principle of boronate affinity [20] and haemoglobin $(\mathrm{Hb})$ by the cyanmethaemoglobin method using a spectrophotometer (Shimadzu UV 2600). Lipid profile (high-density lipoprotein (HDL), total cholesterol (TC), and triglycerides (TG)) was analyzed in plasma using commercially available kits from BioSystems (Barcelona, Spain). Low-density lipoprotein (LDL) concentrations were calculated using the Friedewald formula [21]. Urinary albumin was quantified using a solid-phase immunochemical assay and urinary creatinine by an enzymatic colourimetric test in a fully automated Afinion AS100 Analyzer (AxisShield, Norway) [22], and then the urinary albumin-tocreatinine ratio (UACR) (expressed as $\mathrm{mg} / \mathrm{g}$ creatinine) was calculated.

2.2.3. Cutoffs for Covariates. FBG $<110 \mathrm{mg} / \mathrm{dL}$ was considered as normal, $110-125 \mathrm{mg} / \mathrm{dL}$ as impaired fasting glucose (IFG), and $\geq 126 \mathrm{mg} / \mathrm{dL}$ as diabetic [23]. An HbAlc value of $<6.5 \%$ was considered as normal [24]. The prevalence of anemia was calculated based on the $\mathrm{Hb}$ levels. 


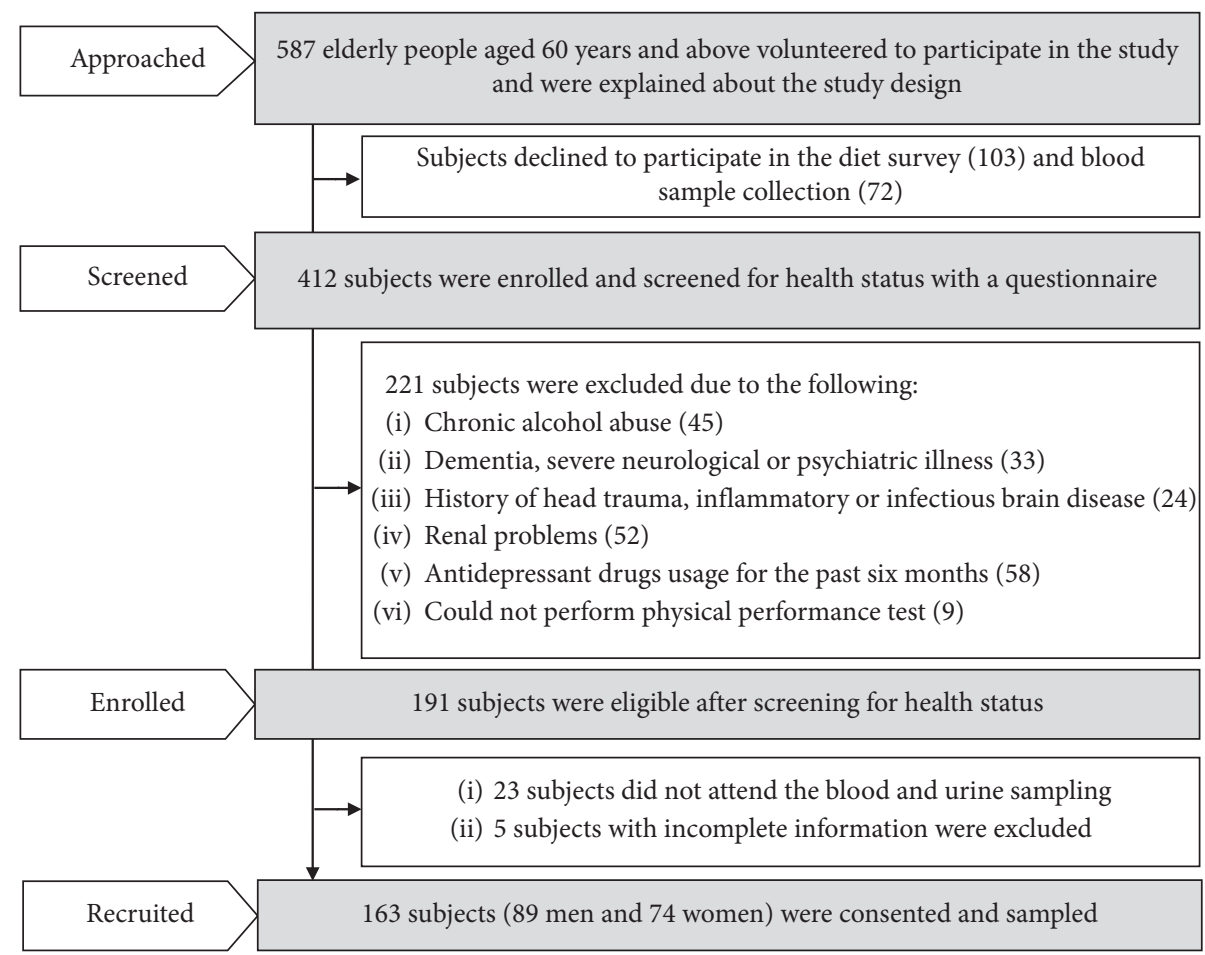

FIGURE 1: Flowchart showing the recruitment and selection of study participants.

Anemia was defined as a $\mathrm{Hb}$ value $<13.0 \mathrm{~g} / \mathrm{dL}$ in men and $<12.0 \mathrm{~g} / \mathrm{dL}$ in women [25]. The optimal plasma concentration of TC was $<200 \mathrm{mg} / \mathrm{dL},<130 \mathrm{mg} / \mathrm{dL}$ for LDL, $<150 \mathrm{mg} /$ $\mathrm{dL}$ for $\mathrm{TG}$, and low HDL was $\geq 40 \mathrm{mg} / \mathrm{dL}$ in men and $\geq 50 \mathrm{mg} / \mathrm{dL}$ in women [26]. According to the National Kidney Foundation, UACR $<30 \mathrm{mg} / \mathrm{g}$ was considered as normal, $30-300 \mathrm{mg} / \mathrm{g}$ as microalbuminuria, and $\geq 300 \mathrm{mg} / \mathrm{g}$ as overt nephropathy [27].

2.2.4. Dietary Assessment. Individual dietary intake was assessed in a subset of the samples $(n=88,48$ men and 40 women) using a systematic random sampling procedure. A $24 \mathrm{~h}$ dietary recall was carried out on three different days $(2$ nonconsecutive weekdays and one weekend day) to capture intra- and interindividual variation [28]. The member of the household who cooked food for the entire household was interviewed for dietary intake of individuals during the previous $24 \mathrm{~h}$, excluding festival, function, and fasting days. A standardized set of twelve cups and two spoons were used as visual tools for assessing portion sizes [29]. The raw ingredients used for the food preparation were weighed using a portable electronic digital diet scale (Seca Culina $\left.852^{\circledR}\right)$. The quantities of raw foods were computed from the intakes of cooked foods (intakes of the raw food by the individual $=$ (quantity of raw food in the preparation/total cooked quantity of food) $\times$ individual intake of cooked food).

The nutritive value of raw foods was calculated using the Indian Food-Composition Tables (IFCTs) [30], while the United States Department of Agriculture Food and Nutrient Database [31] was used for those foods that did not have a nutrient value in the IFCT. After correction for moisture, the nutritive values of these two databases were comparable (within 10-20\% variation). The total daily consumption was computed based on the above mentioned nutritive value databases and by taking the average of 3 days of diet survey, using the in-house software.

(1) Probability of Adequacy (PA). The adequacy of micronutrients was assessed using the probability approach which relates an individual's usual intake of nutrients to the distribution of requirements for a particular life stage and gender group using estimated average requirement (EAR) values and its standard deviation (SD) [32-34]. Then, the PA was computed using the "CDFNORM" function in SPSS software. CDFNORM function is a cumulative probability distribution of nutrient requirements, assumed to be a normal distribution, and is expressed as area under the probability curve. This function computes by plotting each individual's intake data from the study population and constructs a risk curve using the requirement (EAR and SD) distribution of the group $(Z$ score $=($ intake $-\mathrm{EAR}) / \mathrm{SD}$ of the requirement). Then, the risk curve was compared to the distribution of intakes of the study population to determine what proportion of the population has an inadequate intake. Thus, PA determines the probability that an individual's intake in a group meets the requirements, and then, their mean of the individual probabilities is obtained, which is used to estimate the prevalence of adequacy of a particular nutrient $[34,35]$. Hence, the micronutrient adequacy was evaluated by calculating the PA for fourteen micronutrients that are of public health importance in this study: vitamins such as A, C, B1, B2, niacin, B6, folate, and B12, and minerals 
such as calcium, zinc, iron, magnesium, phosphorus, and selenium. The recommended EAR, as set by the Institute of Medicine (IOM) (National Academies, Food and Nutrition Board) [36], according to the sex and age group, was considered for the calculation of PA. The resulting value for PA ranged from 0 to $100 \%$, and an overall mean PA (MPA) was calculated by averaging the PA across the fourteen nutrients. The prevalence of inadequacy was defined by considering MPA below 50\% (MPA < 0.5) [36, 37].

(2) Nutrient Density. Nutrient density is the ratio of the amount of nutrient intake in the diet to the energy provided by the same diet and is expressed as the amount of the nutrient per $1,000 \mathrm{kcal}$ of energy [38].

2.3. Frailty Indicators. Five indicators were assessed to measure frailty. These included (i) weakness, (ii) weight loss, (iii) physical activity level, (iv) exhaustion, and (v) gait speed (GS).

2.3.1. Weakness. Handgrip strength (HGS) was measured to estimate the physical weakness of the participant using a Jamar hand-held dynamometer [6]. The cutoff for HGS stratified by gender and BMI is depicted in Supplementary Table 1A. To determine the cutoff point for defining the lowest quartile on measures of HGS, the $25^{\text {th }}$ percentile was used [39].

2.3.2. Weight Loss. Self-reported unintentional weight loss was assessed in response to the question, "Have you lost any weight during the past 12 months?" Those reporting a weight loss of $4.5 \mathrm{~kg}$ or more in the previous year were considered [6].

2.3.3. Low Physical Activity Level. A question was asked to the participants, "Taking into account both work and leisure, would you say that you are very, fairly, not very, or not at all physically active?" Those reported themselves as not very or not at all physically active were considered physically inactive [7].

2.3.4. Exhaustion. A question was asked to the participants, "Are you feeling worn out or exhausted?" The participants who reported themselves as exhausted were considered as exhausted [7].

2.3.5. Gait Speed (GS). It was assessed by a standard timed walking test in which a five-meter length of the string was laid along the ground, and the participants were asked to get up from the chair and walk normally to the end of the string, turn round and walk back again, and sit on the chair [7]. Due to the change in stride length of a person, the GS varies with height. The cutoff for GS stratified by gender and height is depicted in Supplementary Table 1B. To determine the cutoff point for defining the lowest quartile on measures of GS, the $25^{\text {th }}$ percentile was used [39].
On a scale of 5 , a person who gets a score of $0-2$ was categorized as nonfrail and $3-5$ score as a frail person $[6,40]$.

2.4. Statistical Analyses. Data analyses were performed using the SPSS software package (version 19.0, SPSS Inc, Chicago, IL). As most of the data were skewed, the anthropometric parameters, clinical variables, food groups, and nutrients by frailty status were reported using medians and $25^{\text {th }}\left(P_{25}\right)$ and $75^{\text {th }}\left(P_{75}\right)$ percentiles, and comparisons for the same were carried out by the Mann-Whitney $U$ test. The median values of the variables (HGS and GS) were compared across the age groups and gender using a Kruskal-Wallis test with pairwise-multiple comparisons. The chi-square $\left(\chi^{2}\right)$ test was used for testing the association between categorical variables. Student's $t$-test was used to compare the PA and MPA by frailty status. The food groups and nutrients were divided into tertiles, and the associations between frailty status and the dietary variables were examined using the $\chi^{2}$ test. Statistical significance was considered at $P<0.05$.

\section{Results}

The median $\left(P_{25}-P_{75}\right)$ age of the participants was 65.0 (62.0-70.0) (Table 1). The gender (men, 55\%; women, $45 \%$ ) and the age-wise (60-65 years, $55 \%$; $\geq 66$ years, $45 \%)$ distributions were almost similar in both groups. The majority of the subjects were baccalaureate graduates and above (35.2\%) and were consuming mixed diets (72\%). About 3\% of the subjects were underweight, $24 \%$ had a normal BMI, and $73 \%$ were overweight and obese.

3.1. Prevalence of Frailty and Its Association with Age and Gender. According to Fried frailty phenotype criteria, 20\% of the study participants were frail and $80 \%$ were nonfrail (Figure 2(a)). We determined the association of two direct measures of frailty (HGS and GS) with age and gender. The HGS was observed to be lower with increasing age considering both genders, though it was not significant. The HGS was significantly higher in men compared to women in both the age groups (Figure 2(b)). There was no difference in GS between the age groups among men, but there was a difference between the age groups among women. The GS of men was significantly different when compared to women of respective age groups (Figure 2(c)).

3.2. Nutritional Status of the Study Participants by Frailty Status. Median age and UACR were significantly higher, whereas $\mathrm{Hb}$ was significantly lower in the frail group compared to the nonfrail group. No significant $(P<0.05)$ difference was observed for other variables (Table 1).

The prevalence of frailty in the $\geq 66$-year age group (30.1\%) was significantly higher when compared to the 60-65-year age group (12.2\%). By gender, the prevalence of frailty was significantly higher in women (32.4\%) than men $(10.1 \%)$. Nonearning $(41.5 \%)$ participants had a significantly higher prevalence compared to earning (6.4\%) participants. Uneducated and participants of lower education had a 
TABle 1: Comparison of anthropometric details and blood parameters between nonfrail and frail participants.

\begin{tabular}{lccc}
\hline Parameter & $\begin{array}{c}\text { Pooled }(n=163), \\
\text { median }\left(P_{25}-P_{75}\right)\end{array}$ & $\begin{array}{c}\text { Nonfrail }(n=130), \\
\text { median }\left(P_{25}-P_{75}\right)\end{array}$ & $\begin{array}{c}\text { Frail }(n=33), \\
\text { median }\left(P_{25}-P_{75}\right)\end{array}$ \\
\hline Age, years & $65.0(62.0-70.0)$ & $64.0(61.0-68.0)$ & $70.0(65.0-76.0)$ \\
Height, cm & $160(152-166)$ & $161(154-167)$ & $155(150-163)$ \\
Weight, kg & $66.6(58.6-73.7)$ & $66.9(59.2-73.7)$ & $61.1(49.0-72.3)$ \\
BMI, kg/m & $25.7(22.7-28.5)$ & $26.0(23.0-28.5)$ & $24.3(21.7-29.2)$ \\
WC, cm & $94.0(85.1-101.6)$ & $94.0(86.4-101.6)$ & $91.4(83.8-99.1)$ \\
HC, cm & $99.1(92.2-106.7)$ & $99.1(94.0-106.7)$ & $98.3(90.2-106.7)$ \\
WHR & $0.95(0.89-0.99)$ & $0.95(0.9-1.0)$ & $0.93(0.87-0.98)$ \\
SBP, mmHg & $140.5(130.0-162.0)$ & $140.0(128.0-160.0)$ & $150.0(134.0-171.0)$ \\
DBP, mmHg & $83.0(76.0-91.0)$ & $81.0(76.0-90.0)$ & $85.0(77.0-92.0)$ \\
FBG, mg/dl & $110.0(97.0-136.0)$ & $108.5(98.0-135.0)$ & $112(97.0-147.0)$ \\
TC, mg/dl & $176.7(144.2-208.0)$ & $177.8(148.2-209.6)$ & $171.3(139.3-198.8)$ \\
HDL, mg/dl & $41.7(33.4-49.3)$ & $41.0(33.0-48.9)$ & $45.8(34.7-50.3)$ \\
LDL, mg/dl & $110.4(83.1-141.0)$ & $111.3(84.0-145.5)$ & $110.1(76.0-128.7)$ \\
TG, mg/dl & $101.7(76.7-141.5)$ & $103.4(78.7-144.0)$ & $96.1(69.9-129.7)$ \\
Hb, g/dl & $13.4(12.4-14.6)$ & $13.6(12.6-14.7)$ & 0.329 \\
HbAlc, $\%)$ & $6.4(5.8-7.4)$ & $6.4(5.8-7.4)$ & 0.214 \\
Creatinine, mg/dl & $1.0(0.9-1.1)$ & $1.0(0.9-1.1)$ & 0.079 \\
UACR, mg/g creatinine & $15.1(8.3-35.2)$ & $13.4(8.1-29.8)$ & 0.634 \\
BMt body mass & 0.705 \\
\end{tabular}

BMI: body mass index; WC: waist circumference; WHR: waist-to-hip ratio; SBP: systolic blood pressure; DBP: diastolic blood pressure; FBG: fasting blood glucose; TC: total cholesterol; HDL: high-density lipoprotein cholesterol; LDL: low-density lipoprotein cholesterol; TG: triglycerides; Hb: haemoglobin; HbA1c: glycosylated haemoglobin; UACR: urinary albumin-to-creatinine ratio; $P_{25}: 25^{\text {th }}$ percentile; $P_{75}: 75^{\text {th }}$ percentile. Values represent medians, $25^{\text {th }}$ and $75^{\text {th }}$ percentiles. $P<0.05$ was considered to be significant.

significantly higher prevalence of frailty compared to those who had higher education (Table 2).

The median $\left(P_{25}-P_{75}\right)$ intakes of cereals and millets, pulses and legumes, green leafy vegetables, roots and tubers, nuts and oilseeds, spices and condiments, fruits, and fats and oils and all the nutrients except for vitamin B12 were significantly lower in the frail group compared to the nonfrail group (Table 3). Dietary energy intake, a proxy for food intake, was significantly low in the frail group. The major contributor to energy was carbohydrates $(\sim 56 \%)$ and fat $(\sim 28 \%)$, and the protein intake was near to optimal $(\sim 11 \%)$ in both the groups (Table 3).

3.3. Probability of Adequacy by Frailty Status. The PA of vitamin A $(P=0.038)$, vitamin $\mathrm{C}(P=0.040)$, thiamine $(P=0.001)$, folate $(P=0.013)$, vitamin B6 $(P=0.003)$, calcium $\quad(P=0.013)$, zinc $(P=0.042), \quad$ magnesium $(P<0.001)$, phosphorus $(P=0.01)$, and selenium $(P=0.042)$ was significantly lower in the frail group compared to the nonfrail group (Figure 3). Noticeably, the MPA across the fourteen micronutrients was $35 \%$ and was significantly higher in nonfrail (38\%) compared to the frail group (25\%) (Figure 3). The risk of micronutrient inadequacy $(\mathrm{MPA}<0.5)$ was about $84 \%$ in the study subjects and was associated with frailty status but not significant $(P<0.05)$ (Figure 4). The prevalence of inadequacy $(\mathrm{MPA}<0.5)$ was higher in the frail group $(95 \%)$ compared to the nonfrail group (81\%) (Figure 4).

3.4. Food and Nutrient Quality of the Participants by Frailty Status. The nutrient density and nutrients per $\mathrm{kg}$ body weight were similar between frail and nonfrail groups (Supplementary Table 2).

3.5. Association of Food Groups and Nutrient Intake with Frailty. Association of food groups and nutrient intake according to the tertiles in frail participants is shown in Supplementary Tables 3A and 3B. Significantly high prevalence of frailty was observed in the lowest tertile intakes of most of the food groups and nutrients compared to the highest tertile. Model 1 (adjusted for age and gender) and model 2 (adjusted for age, gender, and energy) adjustments did not result in any change in the existing associations.

\section{Discussion}

Proper nutrition plays an essential role in maintaining good health. As nutritional status is an essential factor contributing to frailty, inadequate food intake among older adults, due to dentition problems, anorexia nervosa, social isolation, and economic hardships, makes them predisposed to frailty. If assessed beforehand, the process of frailty among older adults can be postponed, and hence, they may be provided with a healthy life.

Studies reported in India showed a varied prevalence $(16.3-55.5 \%)$ of frailty [11-13]. In the present study, the prevalence of frailty was $20 \%$. This low-end prevalence of frailty in this study may be due to age, ethnicity, and dietary habits compared to the reported studies that were done in higher age groups (65 years).

Physical inactivity results in loss of muscle mass due to the imbalance between synthesis and degradation of muscle proteins, even in healthy older adults. This situation can worsen owing to the steady loss of metabolic reserves and 


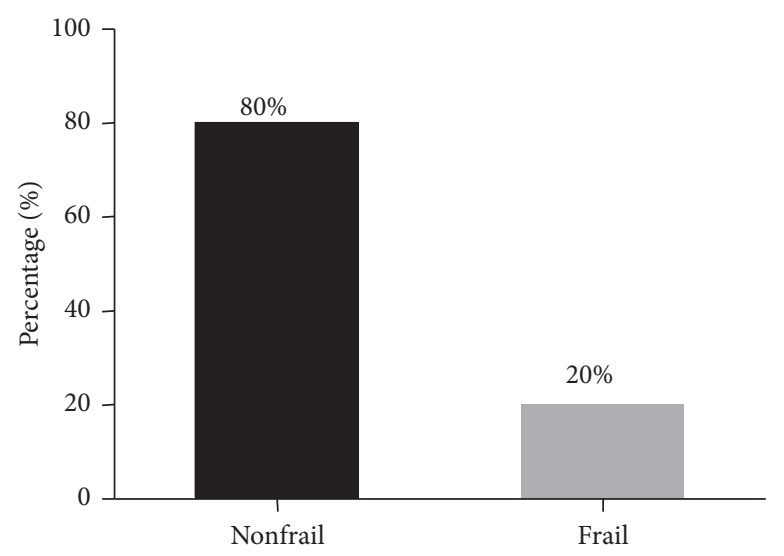

(a)

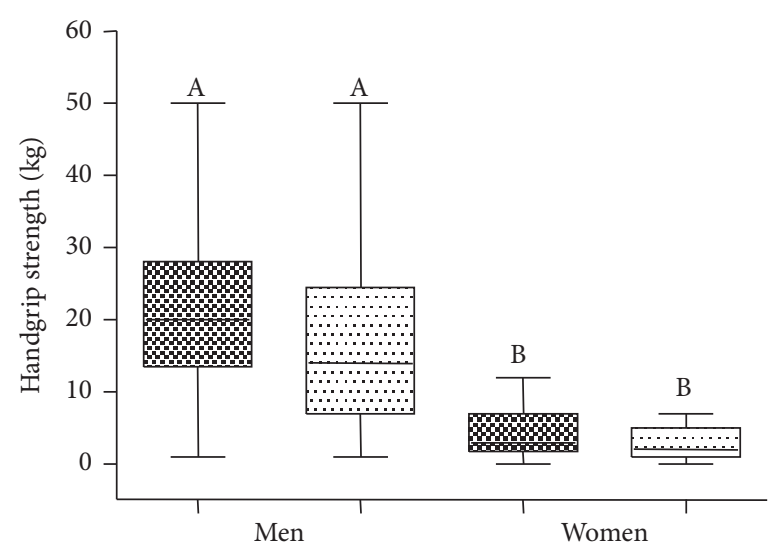

\$60-65 years $\geq 66$ years

(b)

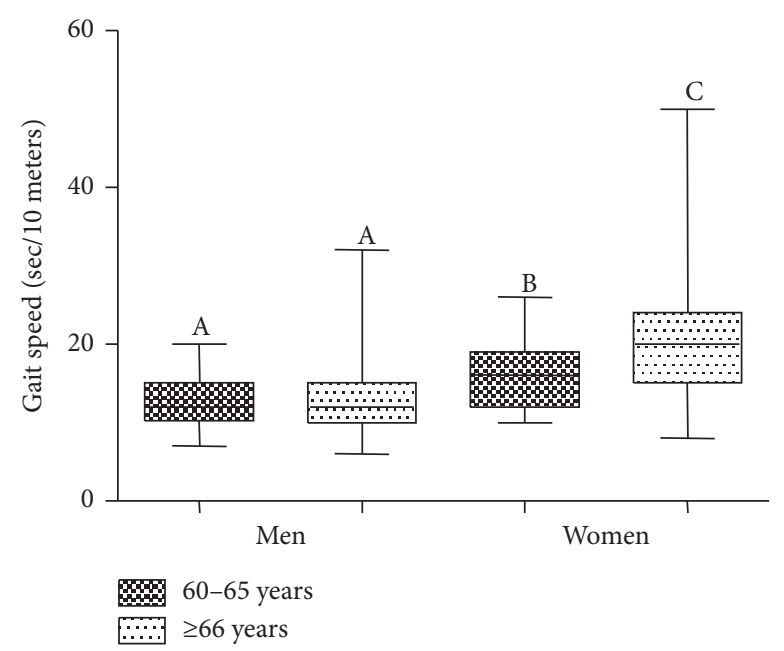

(c)

Figure 2: Prevalence of frailty (a), the relation of handgrip strength (b), and gait speed (c) with age and gender. Significant differences $(P<0.05)$ of median values with age and gender are indicated by different superscript letters $(\mathrm{A}, \mathrm{B}$, and $\mathrm{C})$ above the bars.

functional capacity. Handgrip strength and GS were found to be the predictors of physical functional status and allcause mortality in older adults [41]. This study has shown a trend in HGS reduction with increasing age, and men were stronger than women, in concurrence with the previous studies [39]. This might be due to a decrease in the number and size of muscle fibers with progressing age (type II) and the difference in dietary patterns (especially protein intake). A study reported that older adults in India had significantly poor muscle strength than in the United States [14]. A crosssectional study among older North Indians revealed that the GS was found to be lower with increasing age and higher with increasing height in both genders [39]. In agreement with this report, we have observed similar findings in the present study.

The findings of the current study concur with the recent studies that the prevalence of frailty increased with age, more so in women and participants having lower education and income $[6,11]$. A Study on global AGEing and adult health (SAGE) revealed that in low- and middle-countries, both frailty and disability increased with age and were higher in women [11]. In a Cardiovascular Health Study (CHS) and SAGE study, education and income were found to be related to frailty $[11,42]$. The gender difference in frailty may be due to lower lean mass, strength, differences in patterns of physical activity and performance, longer life expectancy, and higher morbidity rates and more likely to live alone with the consequence of poor nutrition in women than men.

The adequacy of most of the nutrients was low in the frail group, and the MPA across the fourteen micronutrients was $25 \%$. The prevalence of frailty was observed to be higher in the lowest tertile of most of the nutrient intake and was almost double compared to the highest tertile. The associations remained the same even after adjusted for model 1 (age and gender) and model 2 (age, gender, and energy). Similarly, Health, Aging, and Body Composition (Health$\mathrm{ABC}$ ) study among community-dwelling older adults found that low intake of dietary protein was associated with a $40 \%$ loss of lean body mass [43] and the protein intake is the primary factor responsible for muscle protein anabolism. 
TABLE 2: Association of sociodemographic details and anthropometry and blood parameters with frailty status.

\begin{tabular}{|c|c|c|c|c|}
\hline Parameter & Pooled $(n=163)$ & Nonfrail $(n=130)$ & Frail $(n=33)$ & $P$ value \\
\hline \multicolumn{5}{|l|}{ Age, years } \\
\hline $60-65$ & 90 & $79(87.8 \%)$ & $11(12.2 \%)$ & \multirow{2}{*}{0.005} \\
\hline$\geq 66$ & 73 & $51(69.9 \%)$ & $22(30.1 \%)$ & \\
\hline \multicolumn{5}{|l|}{ Gender } \\
\hline Men & 89 & $80(89.9 \%)$ & $9(10.1 \%)$ & \multirow{2}{*}{$<0.001$} \\
\hline Women & 74 & $50(67.6 \%)$ & $24(32.4 \%)$ & \\
\hline \multicolumn{5}{|l|}{ Food habits } \\
\hline Vegetarian & 45 & $32(71.1 \%)$ & $13(28.8 \%)$ & \multirow{2}{*}{0.426} \\
\hline Mixed diet & 118 & $91(77.1 \%)$ & $27(22.9 \%)$ & \\
\hline \multicolumn{5}{|l|}{ Occupation } \\
\hline Earning & 47 & $44(93.6 \%)$ & $3(6.4 \%)$ & \multirow{2}{*}{$<0.001$} \\
\hline Nonearning & 41 & $24(58.5 \%)$ & $17(41.5 \%)$ & \\
\hline \multicolumn{5}{|l|}{ Education } \\
\hline Uneducated & 7 & $4(57.1 \%)$ & $3(42.9 \%)$ & \multirow{4}{*}{$<0.001$} \\
\hline $1-8$ standard & 20 & $9(45.0 \%)$ & $11(55.0 \%)$ & \\
\hline $9-12$ standard & 30 & $26(86.7 \%)$ & $4(13.3 \%)$ & \\
\hline Graduation and above & 31 & $29(93.5 \%)$ & $2(6.5 \%)$ & \\
\hline \multicolumn{5}{|l|}{ BMI, $\mathrm{kg} / \mathrm{m}^{2}$} \\
\hline$<18.5$ & 5 & $3(60.0 \%)$ & $2(40.0 \%)$ & \multirow{3}{*}{0.300} \\
\hline $18.5-23$ & 39 & $29(74.4 \%)$ & $10(25.6 \%)$ & \\
\hline$\geq 23$ & 119 & $98(82.4 \%)$ & $21(17.6 \%)$ & \\
\hline \multicolumn{5}{|l|}{$\mathrm{WC}, \mathrm{cm}$} \\
\hline Normal & 29 & $20(69.0 \%)$ & $9(31.0 \%)$ & \multirow{2}{*}{0.279} \\
\hline Abdominal obesity & 94 & $74(78.7 \%)$ & $20(21.3 \%)$ & \\
\hline \multicolumn{5}{|l|}{ WHR } \\
\hline Normal & 6 & $3(50.0 \%)$ & $3(50.0 \%)$ & \multirow{2}{*}{0.118} \\
\hline Central obesity & 117 & $91(77.8 \%)$ & $26(22.2 \%)$ & \\
\hline \multicolumn{5}{|l|}{ Hypertension (HTN), mmHg } \\
\hline Normal $(\mathrm{SBP}<140, \mathrm{DBP}<90)$ & 114 & $93(81.6 \%)$ & $21(18.4 \%)$ & \\
\hline HTN $($ SBP $\geq 140$, DBP $\geq 90)$ & 49 & $37(75.5 \%)$ & $12(24.5 \%)$ & 0.377 \\
\hline $\mathrm{FBG}, \mathrm{mg} / \mathrm{dl}$ & & & & \\
\hline$<110$ & 83 & $68(81.9 \%)$ & $15(18.1 \%)$ & \\
\hline $110-125$ & 32 & $26(81.3 \%)$ & $6(18.8 \%)$ & 0.619 \\
\hline$\geq 126$ & 48 & $36(75.0 \%)$ & $12(25.0 \%)$ & \\
\hline $\mathrm{TC}, \mathrm{mg} / \mathrm{dl}$ & & & & \\
\hline$<200$ & 113 & $88(77.9 \%)$ & $25(22.1 \%)$ & \\
\hline$\geq 200$ & 50 & $42(84.0 \%)$ & $8(16.0 \%)$ & 0.370 \\
\hline $\mathrm{TG}, \mathrm{mg} / \mathrm{dl}$ & & & & \\
\hline$<150$ & 130 & $102(78.5 \%)$ & $28(21.5 \%)$ & \\
\hline$\geq 150$ & 33 & $28(84.8 \%)$ & $5(15.2 \%)$ & 0.415 \\
\hline $\mathrm{HDL}, \mathrm{mg} / \mathrm{dl}$ & & & & \\
\hline Male: $<40$; female: $<50$ & 97 & $77(79.4 \%)$ & $20(20.6 \%)$ & \\
\hline Male: $\geq 40$; female: $\geq 50$ & 66 & $53(80.3 \%)$ & $13(19.7 \%)$ & 0.886 \\
\hline $\mathrm{LDL}, \mathrm{mg} / \mathrm{dl}$ & & & & \\
\hline$<130$ & 131 & $102(77.9 \%)$ & $29(22.1 \%)$ & \\
\hline$\geq 130$ & 32 & $28(87.5 \%)$ & $4(12.5 \%)$ & 0.224 \\
\hline $\mathrm{Hb}, \mathrm{g} / \mathrm{dl}$ & & & & \\
\hline Male: $<13$; female: $<12$ & 30 & $23(76.7 \%)$ & $7(23.3 \%)$ & \\
\hline Male: $\geq 13$; female: $\geq 12$ & 113 & $93(82.3 \%)$ & $20(17.7 \%)$ & 0.497 \\
\hline HbAlc (\%) & & & & \\
\hline$<6.5$ & 94 & $74(78.7 \%)$ & $20(21.3 \%)$ & 0295 \\
\hline$\geq 6.5$ & 69 & $55(79.7 \%)$ & $14(20.3 \%)$ & 0.295 \\
\hline UACR, mg/g & & & & \\
\hline$<30$ & 77 & $63(81.8 \%)$ & $14(18.2 \%)$ & \\
\hline $30-300$ & 29 & $18(62.1 \%)$ & $11(37.9 \%)$ & 0.097 \\
\hline$\geq 300$ & 3 & $2(66.7 \%)$ & $1(33.3 \%)$ & \\
\hline Diabetes & & & & \\
\hline Yes & 62 & $46(74.2 \%)$ & $16(25.8 \%)$ & \\
\hline No & 63 & $49(77.8 \%)$ & $14(22.2 \%)$ & 0.639 \\
\hline
\end{tabular}


TABle 2: Continued.

\begin{tabular}{|c|c|c|c|c|}
\hline Parameter & Pooled $(n=163)$ & Nonfrail $(n=130)$ & Frail $(n=33)$ & $P$ value \\
\hline \multicolumn{5}{|l|}{ Cataract } \\
\hline Yes & 37 & $26(70.3 \%)$ & $11(29.7 \%)$ & \multirow{2}{*}{0.277} \\
\hline No & 87 & $69(79.3 \%)$ & $18(20.7 \%)$ & \\
\hline \multicolumn{5}{|c|}{ Osteoarthritis } \\
\hline Yes & 36 & $24(66.7 \%)$ & $12(33.3 \%)$ & \multirow{2}{*}{0.094} \\
\hline No & 88 & $71(80.7 \%)$ & 17 (19.3\%) & \\
\hline
\end{tabular}

BMI: body mass index; WC: waist circumference; WHR: waist-to-hip ratio; HTN: hypertension; SBP: systolic blood pressure; DBP: diastolic blood pressure; FBG: fasting blood glucose; TC: total cholesterol; HDL: high-density lipoprotein cholesterol; LDL: low-density lipoprotein cholesterol; TG: triglycerides; Hb: haemoglobin; HbAlc: glycosylated haemoglobin; UACR: urinary albumin-to-creatinine ratio. Values represent percentages (\%). $P<0.05$ was considered to be significant.

TABle 3: Median $\left(P_{25}-P_{75}\right)$ intake of food groups and nutrients by frailty status.

\begin{tabular}{|c|c|c|c|c|}
\hline Food groups/nutrients & $\begin{array}{c}\text { Pooled }(n=88) \\
\text { median }\left(P_{25}-P_{75}\right)\end{array}$ & $\begin{array}{l}\text { Nonfrail }(n=68) \\
\text { median }\left(P_{25}-P_{75}\right)\end{array}$ & $\begin{array}{c}\text { Frail }(n=20), \\
\text { median }\left(P_{25}-P_{75}\right)\end{array}$ & $P$ value \\
\hline \multicolumn{5}{|l|}{ Food groups } \\
\hline Cereals and millets (g) & $231.4(205.2-277.9)$ & $250.2(208.7-289.6)$ & $204.8(188.0-227.9)$ & 0.001 \\
\hline Pulses and legumes (g) & $40.1(25.4-47.5)$ & $42.3(32.2-51.5)$ & $24.8(17.9-36.5)$ & $<0.001$ \\
\hline Green leafy vegetables (g) & $17.1(11.4-30.9)$ & $18.0(13.5-34.2)$ & $11.9(6.8-23.4)$ & 0.014 \\
\hline Other vegetables $(\mathrm{g})$ & $130.9(78.7-176.2)$ & $131.8(83.8-177.2)$ & $110.9(62.9-173.2)$ & 0.504 \\
\hline Roots and tubers (g) & $56.5(42.4-79.7)$ & $59.4(46.1-84.1)$ & $47.1(33.7-60.1)$ & 0.037 \\
\hline Nuts and oilseeds (g) & $8.7(4.6-13.6)$ & $9.9(5.2-14.2)$ & $5.2(3.8-8.2)$ & 0.007 \\
\hline Spices and condiments (g) & $10.4(8.5-12.8)$ & $11.3(9.4-13.2)$ & $7.7(5.1-10.2)$ & $<0.001$ \\
\hline Fruits $(g)$ & $113.2(84.4-189.9)$ & $124.5(92.2-198.6)$ & $100.8(63.2-135.8)$ & 0.019 \\
\hline Animal foods (g) & $20.8(0.0-52.6)$ & $24.0(0.0-58.5)$ & $20.8(0.0-52.6)$ & 0.252 \\
\hline Milk and milk products (g or $\mathrm{ml}$ ) & $269.5(217.7-342.2)$ & $277.0(227.7-349.9)$ & $236.8(183.0-318.8)$ & 0.070 \\
\hline Fats and oils (g) & $29.9(22.5-35.6)$ & $30.7(25.4-36.8)$ & $21.1(16.3-29.0)$ & 0.001 \\
\hline Sugar (g) & $8.2(5.0-11.7)$ & $8.9(5.0-12.3)$ & $7.1(4.8-10.0)$ & 0.265 \\
\hline \multicolumn{5}{|l|}{ Nutrients } \\
\hline Energy (kcal) & $1902(1625-2131)$ & 1977 (1749-2155) & $1484(1317-1762)$ & $<0.001$ \\
\hline Protein $(\mathrm{g})$ & $52.2(43.7-57.1)$ & $54.1(48.6-59.5)$ & $41.6(34.8-49.3)$ & \multirow{2}{*}{$<0.001$} \\
\hline$\%$ of energy intake & 10.9 & 10.9 & 10.9 & \\
\hline Fat $(\mathrm{g})$ & $58.3(50.6-66.0)$ & $60.0(53.4-70.5)$ & $46.1(35.2-58.6)$ & \multirow{2}{*}{$<0.001$} \\
\hline$\%$ of energy intake & 28.1 & 28.4 & 27.2 & \\
\hline Carbohydrates (g) & $263.3(232.0-299.7)$ & $278.1(238.1-310.0)$ & $218.0(197.7-250.0)$ & \multirow{2}{*}{$<0.001$} \\
\hline$\%$ of energy intake & 56.4 & 56.0 & 57.8 & \\
\hline Fiber $(\mathrm{g})$ & $28.9(24.1-33.3)$ & $30.3(25.4-34.2)$ & $21.0(17.2-28.8)$ & $<0.001$ \\
\hline Vitamin A $(\mu \mathrm{g})$ & $424.1(290.1-646.0)$ & $476.7(323.2-680.4)$ & $324.3(210.7-439.0)$ & 0.012 \\
\hline Thiamine (mg) & $1.03(0.87-1.19)$ & $1.07(0.92-1.2)$ & $0.8(0.66-1.0)$ & $<0.001$ \\
\hline Riboflavin (mg) & $0.86(0.71-1.02)$ & $0.9(0.75-1.0)$ & $0.72(0.63-0.83)$ & 0.005 \\
\hline Niacin $(\mathrm{mg})$ & $8.4(7.0-9.8)$ & $8.8(7.3-10.2)$ & $6.6(5.7-7.9)$ & $<0.001$ \\
\hline Vitamin B6 (mg) & $1.0(0.85-1.2)$ & $1.08(0.9-1.24)$ & $0.82(0.68-0.92)$ & $<0.001$ \\
\hline Folate $(\mu \mathrm{g})$ & $227.4(186.3-274.6)$ & $237.6(198.2-280.7)$ & $179.5(146.5-226.3)$ & 0.001 \\
\hline Vitamin B12 $(\mu \mathrm{g})$ & $0.54(0.41-1.01)$ & $0.55(0.41-1.03)$ & $0.5(0.43-0.96)$ & 0.984 \\
\hline Vitamin C (mg) & $73.6(55.2-92.0)$ & $81.8(57.6-96.3)$ & $57.3(37.5-74.6)$ & 0.003 \\
\hline Calcium (mg) & $590.3(473.5-706.6)$ & $623.7(522.0-729.5)$ & $482.8(394.7-593.8)$ & 0.002 \\
\hline Phosphorus (mg) & $932.3(776.4-1066.3)$ & $969.6(848.3-1079.7)$ & $742.6(613.2-875.3)$ & $<0.001$ \\
\hline Iron $(\mathrm{mg})$ & $11.0(8.7-12.6)$ & $11.3(9.8-13.1)$ & $8.4(5.9-11.1)$ & $<0.001$ \\
\hline Zinc (mg) & $6.8(5.9-8.1)$ & $7.2(6.2-8.2)$ & $5.4(4.7-6.7)$ & $<0.001$ \\
\hline Sodium (mg) & $315.9(268.5-381.1)$ & $329.0(290.9-389.7)$ & $262.4(217.1-294.3)$ & $<0.001$ \\
\hline Potassium (mg) & $1825.9(1538.2-2222.7)$ & $1899.5(1619.3-2325.4)$ & $1384.7(1088.6-1647.5)$ & $<0.001$ \\
\hline Selenium $(\mu \mathrm{g})$ & $36.0(25.8-48.6)$ & $38.9(29.5-49.0)$ & $24.4(17.9-41.0)$ & 0.013 \\
\hline
\end{tabular}

$P_{25}$ : 25th percentile; $P_{75}: 75$ th percentile. Values represent medians, 25th and 75th percentiles, and are expressed per day. $P<0.05$ was considered to be significant.

Low intake of protein and vitamins D, E, C, and folate after adjusted for energy intake has been shown to be independently associated with frailty in the InCHIANTI study [10]. Impairment of mitochondrial function is a hallmark of frailty development [44], which may be influenced by the deficiency of micronutrients. The depletion of mitochondrial function in muscles causes diminished energy production, which may lead to fatigue and weakness in frail individuals. Likewise, in the present study, inadequate intakes by the frail subjects as apparent by a higher prevalence of inadequacy (MPA < 0.5) (95\%) might affect the mitochondrial function in muscles which are in turn responsible for the increased 


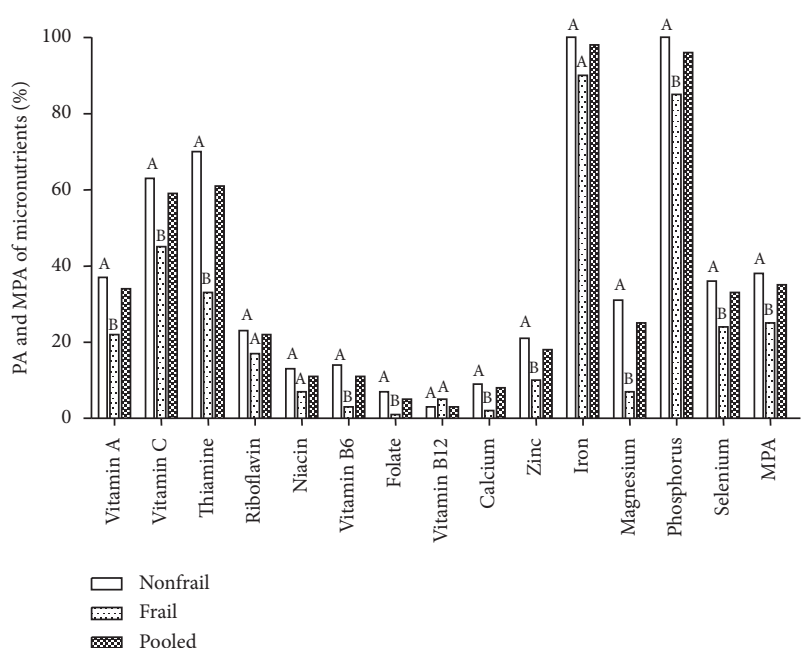

FIgURe 3: Probability of adequacy and mean probability of adequacy of micronutrients among nonfrail and frail participants. PA, probability of adequacy; MPA, mean probability of adequacy. Pooled data represent the total number of samples $(n=88)$. Mean values between the groups were compared by Student's $t$-test. Data represent $(\%)$ adequacy, and significant differences $(P<0.05)$ of mean values between the groups are indicated by different superscript letters (A and B) above the bars.

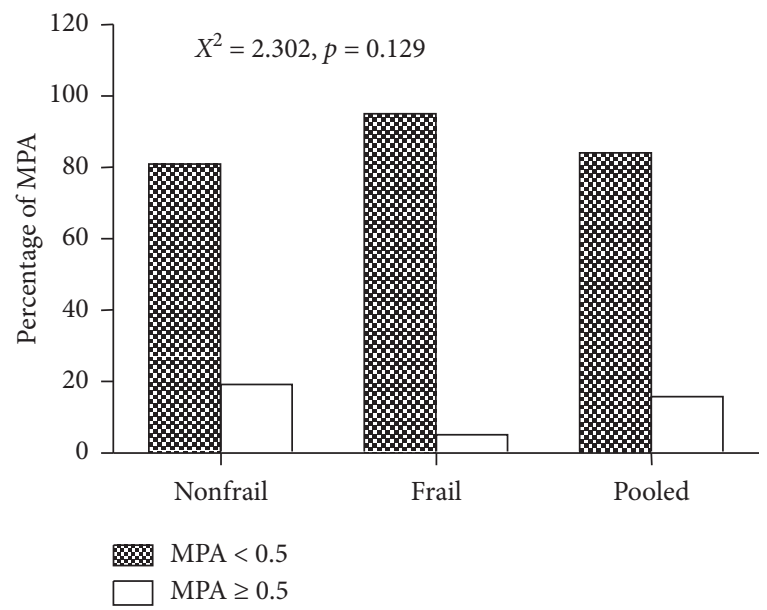

FIGURE 4: Association of the mean probability of adequacy (MPA) with frailty status. Data represent $\%$ inadequacy $(<0.5)$ and $\%$ adequacy $(\geq 0.5)$ of micronutrients. Pooled data represent the total number of samples $(n=88) . \quad P<0.05$ was considered to be significant.

physical inactivity in frail subjects. Though the amount of food is low in the frail group, the quality of diet is almost equal in both groups as evidenced by nutrient density.

The consumption of fruits and vegetables (rich in micronutrients, antioxidants, and fiber) was observed to be low in frail older adults. A study demonstrated that the consumption of three portions of fruits and two portions of vegetables per day was related to a lower risk of frailty [45]. Another study reported an association between antioxidant deficiency and reduced muscle strength [10]. A similar relation was observed in the present study, wherein lower intakes of antioxidant vitamins ( $\mathrm{A}$ and $\mathrm{C}$ ) and minerals (zinc and selenium) were associated with frailty.

In conclusion, $20 \%$ of the study population was frail, the risk of frailty increased with increasing age, and the women are predisposed more than men. The significant determinants associated with frailty were lower educational status and income. Dietary intakes of food groups and the majority of nutrients were found to be low in frail participants. The prevalence of inadequacy (MPA $<0.5)$ was about $95 \%$ in the frail group. The findings of the study demonstrated that inadequate nutritional intake could be a contributing factor to frailty among older adults.

\section{Strengths and Limitations}

This is the first study in India that reports the prevalence of frailty and its association with nutritional status among the urban older adults in South India. These findings contribute to the current knowledge of the prevalence of frailty and understanding its association with nutritional status. The diet calculations used in the study do not account for cooking losses. The results are based on the raw data analysis and are independent of sampling weights and are not adjusted for inflated SDs resulting from complex sampling design. The present study population might not be a representation of the entire country concerning geography, food habits, and other cultural variations, which highlights the need for further studies with larger cohorts to substantiate these findings.
Abbreviations
HGS: Handgrip strength
GS: $\quad$ Gait speed
BMI: $\quad$ Body mass index
FBG: $\quad$ Fasting blood glucose
UACR: Urinary albumin-to-creatinine ratio
PA: Probability of adequacy
MPA: Mean probability of adequacy
EAR: Estimated average requirement.

\section{Data Availability}

No data were used to support the findings of this study.

\section{Conflicts of Interest}

All authors declare that there are no conflicts of interest.

\section{Authors' Contributions}

Conception and design were carried out by GBR and TS. Data collection was performed by TS and PSC. Data interpretation and analysis were conducted by GBR, TS, GM, and BNK. Preparation of the manuscript was contributed by TS and GBR. Primary responsibility of the final content was taken by GBR. 


\section{Acknowledgments}

TS acknowledges the research fellowship from the Indian Council of Medical Research, Government of India. The authors are thankful to all the participants in the study. The authors sincerely thank Dr. AT Jotheeswaran, World Health Organization, Geneva, and Dr. Vivian Isaac, Flinders Rural Health, South Australia, for constructive criticism and useful discussion in the preparation of the manuscript. The authors also acknowledge the help of Dr. S. Sreenivasa Reddy and Dr. M. Sivaprasad, National Institute of Nutrition, Hyderabad, in sample collection and the preparation of the manuscript. GBR acknowledges the financial assistance from the Department of Biotechnology, Government of India (grant no. BT/ PR36689/PFN/20/1524/2020).

\section{Supplementary Materials}

Supplementary Table 1A: cutoff values for grip strength for diagnosing frailty. Supplementary Table 1B: cutoff values for gait speed for diagnosing frailty. Supplementary Table 2: quality of food and nutrient intake of the participants in the study. Supplementary Table 3A: association of intake of food groups with frailty status of the participants. Supplementary Table 3B: association of intake of nutrients with frailty status of the participants. (Supplementary Materials)

\section{References}

[1] J. E. Cohen, "Human population: the next half century," Science, vol. 302, no. 5648, pp. 1172-1175, 2003.

[2] United Nations, World Population Ageing, United Nations Department of Economic and Social Affairs, New York, NY, USA, 2017.

[3] M. Cesari, M. Prince, J. A. Thiyagarajan et al., "Frailty: an emerging public health priority," Journal of the American Medical Directors Association, vol. 17, no. 3, pp. 188-192, 2016.

[4] L. P. Fried, L. Ferrucci, J. Darer, J. D. Williamson, and G. Anderson, "Untangling the concepts of disability, frailty, and comorbidity: implications for improved targeting and care," The Journals of Gerontology Series A: Biological Sciences and Medical Sciences, vol. 59, no. 3, pp. M255-M263, 2004.

[5] K. Rockwood, "Conceptual models of frailty: accumulation of deficits," Canadian Journal of Cardiology, vol. 32, no. 9, pp. 1046-1050, 2016.

[6] L. P. Fried, C. M. Tangen, J. Walston et al., "Frailty in older adults: evidence for a phenotype," The Journals of Gerontology Series A: Biological Sciences and Medical Sciences, vol. 56, no. 3, pp. M146-M157, 2001.

[7] J. At, R. Bryce, M. Prina et al., "Frailty and the prediction of dependence and mortality in low-and middle-income countries: a 10/66 population-based cohort study," $B M C$ Medicine, vol. 13, no. 1, p. 138, 2015.

[8] X. Chen, G. Mao, and S. X. Leng, "Frailty syndrome: an overview," Clinical Interventions in Aging, vol. 9, pp. 433-441, 2014.

[9] B. Gabrovec, G. Veninšek, L. L. Samaniego, A. M. Carriazo, E. Antoniadou, and M. Jelenc, "The role of nutrition in ageing: a narrative review from the perspective of the European joint action on frailty-advantage JA," European Journal of Internal Medicine, vol. 56, pp. 26-32, 2018.

[10] B. Bartali, E. A. Frongillo, S. Bandinelli et al., "Low nutrient intake is an essential component of frailty in older persons," The Journals of Gerontology Series A: Biological Sciences and Medical Sciences, vol. 61, no. 6, pp. 589-593, 2006.

[11] R. B. Biritwum, N. Minicuci, A. E. Yawson et al., "Prevalence of and factors associated with frailty and disability in older adults from China, Ghana, India, Mexico, Russia and South Africa," Maturitas, vol. 91, pp. 8-18, 2016.

[12] J. J. Llibre Rodriguez, A. M. Prina, D. Acosta et al., "The prevalence and correlates of frailty in urban and rural populations in Latin America, China, and India: a 10/66 population-based survey," Journal of the American Medical Directors Association, vol. 19, no. 4, pp. 287-295.e4, 2018.

[13] K. Yashoda and N. Aarti, "Prevalence and determinants of frailty in older adults in India," Indian Journal of Gerontology, vol. 30, no. 3, pp. 364-381, 2016.

[14] S. M. Albert, M. Alam, and M. Nizamuddin, "Comparative study of functional limitation and disability in old age: Delhi and New York city," Journal of Cross-Cultural Gerontology, vol. 20, no. 3, pp. 231-241, 2005.

[15] A. F. Ambrose, M. L. Noone, V. G. Pradeep, B. Johnson, K. A. Salam, and J. Verghese, "Gait and cognition in older adults: insights from the Bronx and Kerala," Annals of Indian Academy of Neurology, vol. 13, no. 6, pp. S99-S103, 2010.

[16] WHO, "Appropriate body-mass index for Asian populations and its implications for policy and intervention strategies," The Lancet, vol. 363, no. 9403, pp. 157-163, 2004.

[17] WHO, Waist Circumference and Waist-Hip Ratio: Report of a WHO Expert Consultation, WHO, Geneva, Switzerland, 2008.

[18] A. V. Chobanian, G. L. Bakris, H. R. Black et al., "The seventh report of the joint national committee on prevention, detection, evaluation, and treatment of high blood pressure," Jama, vol. 289, no. 19, pp. 2560-2571, 2003.

[19] G. S. Dhatt, M. M. Agarwal, Y. Othman, and S. C. Nair, "Performance of the Roche Accu-Chek active glucose meter to screen for gestational diabetes mellitus using fasting capillary blood," Diabetes Technology Therapeutics, vol. 13, no. 2, pp. 1229-1233, 2011.

[20] J. R. Wood, B. M. Kaminski, C. Kollman et al., "Accuracy and precision of the Axis-shield afinion hemoglobin A1c measurement device," Journal of Diabetes Science and Technology, vol. 6, no. 2, pp. 380-386, 2012.

[21] W. C. Roberts, "The Friedewald-Levy-Fredrickson formula for calculating low-density lipoprotein cholesterol, the basis for lipid-lowering therapy," The American Journal of Cardiology, vol. 62, no. 4, pp. 345-346, 1988.

[22] C. Kvam, E. Dworsky, A. T. Campbell et al., "Development and performance of an albumin-creatinine ratio assay on the afinion AS100 analyzer," Point of Care: The Journal of NearPatient Testing \& Technology, vol. 8, no. 1, pp. 16-20, 2009.

[23] WHO, Definition and Diagnosis of Diabetes Mellitus and Intermediate Hyperglycemia Report of a WHO/IDF Consultation, WHO, Geneva, Switzerland, 2006.

[24] WHO, Use of Glycated Haemoglobin (HbA1c) in the Diagnosis of Diabetes Mellitus: Abbreviated Report of a WHO Consultation, WHO, Geneva, Switzerland, 2011.

[25] WHO, Haemoglobin Concentrations for the Diagnosis of Anaemia and Assessment of Severity Vitamin and Mineral Nutrition Information System, WHO, Geneva, Switzerland, 2011. 
[26] NCEP, "Third report of the national cholesterol education program (NCEP) expert panel on detection, evaluation, and treatment of high blood cholesterol in adults (adult treatment panel III) final report," Circulation, vol. 106, no. 25, pp. 3143-3421, 2002.

[27] National Kidney Foundation, "KDOQI clinical practice guideline for diabetes and CKD: 2012 update," American Journal of Kidney Diseases, vol. 60, no. 5, pp. 850-886, 2012.

[28] B. V. S. Thimmayamma and R. Parvathi, Dietary Assessment as Part of Nutritional Status. Text Book of Human Nutrition, Oxford and IBH Publishing Co Pvt Ltd., New Delhi, Delhi, India, 2nd edition, 2003.

[29] S. S. Jose, M. S. Radhika, N. Balakrishna, G. N. V. Brahmam, and G. Bhanuprakash Reddy, "Development of a raw food based quantative food frequency questionnaire for its reproducibility and validity in urban individuals of Hyderabad, India," International Journal of Food and Nutritional Sciences, vol. 3, no. 6, pp. 180-187, 2014.

[30] T. Longvah, R. Ananthan, K. Bhaskarachary, and K. Venkaiah, Indian Food Composition Tables, National Institute of Nutrition, Hyderabad, Telangana, India, 1st edition, 2017.

[31] USDA, Composition of Foods Raw, Processed, Prepared, USDA National Nutrient Database for Standard Reference, Beltsville, MD, USA, 2011.

[32] T. Shalini, M. Sivaprasad, N. Balakrishna et al., "Micronutrient intakes and status assessed by probability approach among the urban adult population of Hyderabad city in South India," European Journal of Nutrition, vol. 58, no. 8, pp. 3147-3159, 2019.

[33] J. A. Foote, S. P. Murphy, L. R. Wilkens, P. P. Basiotis, and A. Carlson, "Dietary variety increases the probability of nutrient adequacy among adults," The Journal of Nutrition, vol. 134, no. 7, pp. 1779-1785, 2004.

[34] NRC, Nutrient Adequacy: Assessment Using Food Consumption Surveys, The National Academies Press, Washington, DC, USA, 1986.

[35] A. L. Carriquiry, "Assessing the prevalence of nutrient inadequacy," Public Health Nutrition, vol. 2, no. 1, pp. 23-34, 1999.

[36] IOM, Dietary Reference Intakes: The Essential Guide to Nutrient Requirements, The National Academics Press, Washington, DC, USA, 2006.

[37] E. Becquey and Y. Martin-Prevel, "Micronutrient adequacy of women's diet in urban Burkina Faso is low," The Journal of Nutrition, vol. 140, no. 1, pp. 2079S-2085S, 2010.

[38] V. Marieke, N. Solomons, S. Muslimatun et al., "Nutrient density as a dimension of dietary quality," Sight and Life Magazine, vol. 32, no. 2, pp. 172-176, 2018.

[39] V. Gunasekaran, J. Banerjee, S. N. Dwivedi, A. D. Upadhyay, P. Chatterjee, and A. P. Dey, "Normal gait speed, grip strength and thirty seconds chair stand test among older Indians," Archives of Gerontology and Geriatrics, vol. 67, pp. 171-178, 2016.

[40] S. Kobayashi, K. Asakura, H. Suga, and S. Sasaki, "High protein intake is associated with low prevalence of frailty among old Japanese women: a multicenter cross-sectional study," Nutrition Journal, vol. 12, no. 1, p. 164, 2013.

[41] V. Chainani, S. Shaharyar, K. Dave et al., "Objective measures of the frailty syndrome (hand grip strength and gait speed) and cardiovascular mortality: a systematic review," International Journal of Cardiology, vol. 215, pp. 487-493, 2016.
[42] C. Hirsch, M. L. Anderson, A. Newman et al., "The association of race with frailty: the cardiovascular health study," Annals of Epidemiology, vol. 16, no. 7, pp. 545-553, 2006.

[43] D. K. Houston, B. J. Nicklas, J. Ding et al., "Dietary protein intake is associated with lean mass change in older, community-dwelling adults: the health, aging, and body composition (health ABC) Study," The American Journal of Clinical Nutrition, vol. 87, no. 1, pp. 150-155, 2008.

[44] P. A. Andreux, M. P. J. Van Diemen, M. R. Heezen et al., "Mitochondrial function is impaired in the skeletal muscle of pre-frail elderly," Scientific Reports, vol. 8, no. 1, p. 8548, 2018.

[45] E. Garcia-Esquinas, B. Rahi, K. Peres et al., "Consumption of fruit and vegetables and risk of frailty: a dose-response analysis of 3 prospective cohorts of community-dwelling older adults," The American Journal of Clinical Nutrition, vol. 104, no. 1, pp. 132-142, 2016. 